\title{
The Physical Fitness Level, Heart Rate, and Heart Rate Recovery among Adolescent Smokers and Non-smokers
}

\author{
Nurvita Risdiana*, Syahruramdhani Syahruramdhani, Armain Suwitno \\ School of Nursing, Faculty of Medicine and Health Sciences, Universitas Muhammadiyah, Yogyakarta, Indonesia
}

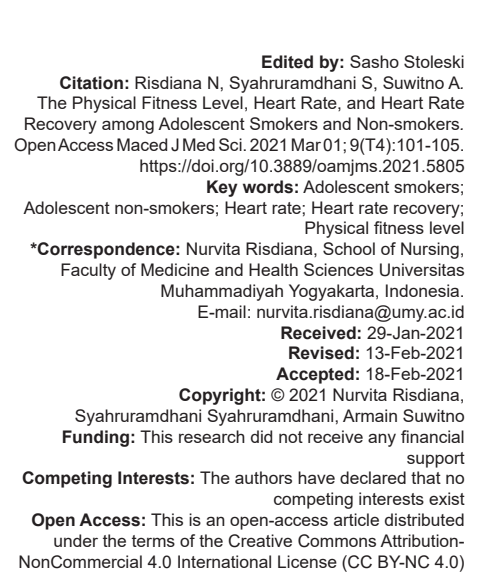

\begin{abstract}
BACKGROUND: Physical fitness level (PFL), heart rate (HR), and HR recovery (HRR1) were expressed the physical performance of an individual which can be the excellent indicators of health. That parameter differentiates the physical condition between a smoker and a non-smoker. At present, studies about them for adolescent smokers and non-smokers are still limited. Furthermore, they can be the prediction of the health indicators in the future.

AIM: The aim of the study was to compare the PFL, HR, and HRR between adolescent smokers and non-smokers

METHODOLOGY: This study was conducted by non-experimental and quantitative research with descriptive comparative design and cross-sectional approach. Mann-Whitney test used to describe the distinction between the PFL of students who are adolescent smokers and adolescent non-smokers. The sample data consist of 65 participants selected by purposive sampling collected using Harvard step test and manual HR measurement.

RESULTS: After gathered data, we concluded that the PFL of adolescent non-smokers in our samples was significantly higher than smokers with recorded results of $p=0.001(p<0.05)$; HR1, HR60, HR90, and HR180 in adolescent smokers were higher than non-smokers with $p=0.00(p<0.05)$; there were no differences between HRR1 in adolescent smokers and non-smokers with $p=0.042(p>0.05)$. Smoking had effects on PFL and HR.

CONCLUSION: The PFL and HR in adolescent non-smokers were better than in smokers but it had no effect on HRR1.
\end{abstract}

\section{Introduction}

Smoking is the leading cause of preventable death, being responsible for the deaths of nearly 6 million people every year worldwide [1]. It is predicted that, by 2030 , tobacco will kill more than 8 million people worldwide each year with $80 \%$ premature death [1]. Smoking prevalence in Indonesia is among the highest in the world. It is reported that $46.8 \%$ of men and $3.1 \%$ of women, aged 10 and older, considered as active smokers [1]. Recently, the percentage of adolescent smokers in Indonesia is as high as $23.9 \%$ among boys and $1.9 \%$ among girls [2]. Furthermore, a National Basic Health Survey in Indonesia reported that the prevalence of smoking among young adults aged between 15 and 24 years old was $26.6 \%$; the highest prevalence was people around the age of 15-19 years amounted up to up to $36 \%$ [3], [4].

Adolescents are individuals with growth rapidly between childhood and adulthood [5]. They, who smoke from their early age, risk their health levels. For the people who smoke in their early age, they are more likely to suffer from smoking premature effect such as cardiovascular and respiratory disorders [6]. Another that, they tend to have lower physical fitness level (PFL) in comparison to the non-smokers [7], autonomic nervous system (ANS) imbalance, [8] and abnormal heart rate recovery (HRR) [9]. PFL is a parameter that characterizes the physical performance of an individual to endure activity before suffering fatigue [10]. Individuals who have higher PFL tend to have better performance and endurance in performing high intense works. There are many aspects that influenced the PFL such as how intense the individuals perform physical activity, how people maintain balanced diet, and whether they are smokers or non-smokers [11], [12], [13].

Smoking reduces the PFL because the substances in the compositions of cigarette [14]. Moslemi-Haghighi et al. [14] stated that the PFL of smokers is significantly lower than of non-smokers. Nicotine, as a well-known substance inside cigarette, leads the inflammation and lung disorder of adolescent smokers. Then, cardiovascular and respiration disorder caused by smoking reduces the PFL for young adolescents. During adolescence, the PFL can be detected from the effect of smoking [15]. It can happen because the adolescents who smoke for 1 year have quite enough nicotine to lead the respiration disorder [7]. PFL in adolescence can be the prediction 
of health performance indicator to know the smoking effect during adolescence.

Besides PFL, smoking also makes the HRR abnormal [14]. HRR is the decreased HR within the minutes after exercise [9] or it can be calculated with the differences of HR between peak HR and $\mathrm{HR}$ in $1 \mathrm{~min}$ later [16]. It acts as an indicator for ANS dysfunction [17]; HRR can be used as the guide to monitor the physical fitness [18]. Since cigarette contents cause the cardiovascular dysfunction, then it can influence the HRR [19], [20]. Furthermore, the HRR in smokers is delayed compared to healthy people [21].

Smoking is the bad habit that influences the risk for degenerative disease in the future. Studies about assessment in PFL and HRR between smokers and non-smokers in Indonesia, especially in Universitas Muhammadiyah Yogyakarta, are still limited. This was the reason why the research for screening the PFL and HRR between smokers and non-smokers at University was conducted. Based on the reason above, this study aims is to know the differences between PFL, HR, and HRR between adolescent smokers and non-smokers. The result can be used as the preventive action. Hopefully, the smokers would quit smoking to improve the PFL and HRR after knowing the HRR.

\section{Methods}

This study is a non-experimental and quantitative research with descriptive comparative design and cross-sectional approach. The participants were 65 students collected by total sampling technique in one faculty of Universitas Muhammadiyah Yogyakarta who were adolescent smokers and adolescent nonsmokers. The participants were chosen by purposive sampling technique for divided into two groups. They were 27 male smokers and 38 male non-smokers. The criterion was the age range of 15-19 years old and for the smokers, each smoked at least one cigarette per day for 1 year. The participants with cardiovascular and respiratory disorders were not permitted in this study. This study obtained an approval from Ethic Commission of Faculty of Medicine and Health Sciences Universitas Muhammadiyah Yogyakarta (Approval Letter Number 229/EP-FKIK-UMY/V/2015).

The PFL was measured by Harvard step test. Harvard step test is the examination for PFL using equipment such as a 48-cm high-platform, a stopwatch, and a metronome. The results were categorized into very poor $<55$, poor 55-64, moderate 64-79, good 80-89, and excellent $\geq 90$.

HR assessment was conducted with manual procedure. The first HR (HR1) measured $1^{\text {st }} \mathrm{s}$ after the participants finished their task using Harvard step test for $1 \mathrm{~min}$ (60 s). The second HR was measured after the participants took a rest for $30 \mathrm{~s}$ or measured on the $90^{\text {th }} \mathrm{s}$ for $1 \mathrm{~min}$ (HR90). The third HR was measured after the participants took a rest for $30 \mathrm{~s}$ or measured on the $180^{\text {th }} \mathrm{s}$ (HR180) for $1 \mathrm{~min}$. HR value is indicated by beats per minutes.

HRR was measured manually. The first HRR (HRR1) was the deviation between first HR which was assessed immediately after the test and the second HR (HR60) (HR60 - HR1) [22].

The preparation in this study included finding the participants who suited the criteria, preparing a stopwatch, a metronome, and a 48-cm high-platform. The participants were students in one faculty of Universitas Muhammadiyah Yogyakarta. First, the researcher gives the information to the participant and the participant was all of the member of students in a one faculty. Second, the participants were given explanations about their roles and asked to fill in the agreement letter before the data were collected.

The procedures of the Harvard steps test were, first, the participants stood up in front of the platform. Second, they put their right feet on the platform. After the stopwatch started, they stepped up and down with metronome rhythm for $5 \mathrm{~min}$. The stopwatch stopped after $5 \mathrm{~min}$. After $5 \mathrm{~min}$, they stopped their activity and then they measured their heartbeats. The heartbeats were measured 3 times. They were HR1, HR90, and HR180. After three heartbeats were obtained, they were counted by the formula (1). The participants who were not able to continue the task before $5 \mathrm{~min}$ stopped and the heartbeats were measured with the formula (1) [23].

$$
\begin{aligned}
\text { Stepupand down } \\
\text { Physical fitness level }=
\end{aligned}
$$

Data analysis. The data were analyzed by univariate, bivariate, and multivariate analysis. MannWhitney test was used to analyze the bivariate, oneway ANOVA and Kruskal-Wallis test were used to analyze the multivariate analysis.

\section{Results}

The participants' characteristics are shown in Table 1. The age range is between 15 and 19 years old with 65 subjects. All of the participants are male with 27 participants in the smoker's group and 38 participants in the non-smokers group.

This study indicates the significant differences of HR1, HR60, HR90, and HR180 with Mann-Whitney 
Table 1: Participant's characteristics

\begin{tabular}{lll}
\hline Criteria & Total & \\
\cline { 2 - 3 } & $\mathrm{n}$ & $\%$ \\
\hline Age (15-19 years old) & 65 & 0 \\
Female & 0 & 100 \\
Male & 65 & $41.53 \%$ \\
Smokers & 27 & $58,46 \%$ \\
Non-smokers & 38 & \\
\hline
\end{tabular}

test among smokers and non-smokers with $p=0.00$ $(p<0.05)$. The smokers represent higher HR than the non-smokers [Table 2]. However, the HRR1 between smokers and non-smokers remain the same with $p=0.42(p>0.05)$ by Mann-Whitney test [Table 2].

Table 2: Heart rate and heart rate recovery among adolescent smokers and non-smokers

\begin{tabular}{|c|c|c|c|c|c|c|c|}
\hline \multirow[t]{2}{*}{ Variables } & \multicolumn{3}{|c|}{ Smokers } & \multicolumn{3}{|c|}{ Non-smokers } & \multirow[t]{2}{*}{$p$ value } \\
\hline & $\mathrm{n}$ & $\%$ & Mean \pm SD & $\mathrm{n}$ & $\%$ & Mean \pm SD & \\
\hline HR1 & 27 & 41.53 & $88.75 \pm 4.77 \mathrm{~s}$ & 38 & 58.46 & $66.61 \pm 7.51$ & $0.00^{*}$ \\
\hline HR60 & 27 & 41.53 & $86.92 \pm 5.00$ & 38 & 58.46 & $64.48 \pm 6.90$ & $0.00^{*}$ \\
\hline HR90 & 27 & 41.53 & $85.81 \pm 5.48$ & 38 & 58.46 & $63.03 \pm 6.91$ & $0.00^{*}$ \\
\hline HR180 & 27 & 41.53 & $82.87 \pm 5.35$ & 38 & 58.46 & $61.09 \pm 6.05$ & $0.00^{*}$ \\
\hline HRR1 & 27 & 41.53 & $1.83 \pm 0,89$ & 38 & 58.46 & $1.99 \pm 1.72$ & 0.42 \\
\hline
\end{tabular}

Kruskal-Wallis and ANOVA tests present the significant differences of HR between the groups of adolescent smokers and non-smokers with $p=0.000$ $(p<0.05)$ and $p=0.004(p<0.05)$ [Table 3]. The HR tends to be lower in the later minutes.

Table 3: The multivariate analysis between heart rate of adolescent smokers and non-smokers

\begin{tabular}{llllll}
\hline Category & HR1 & HR60 & HR90 & HR180 & p value \\
\hline Smokers & $88.75 \pm 4.77$ & $86.92 \pm 5.00$ & $85.81 \pm 5.48$ & $82.87 \pm 5.35$ & $0.000^{*}$
\end{tabular}
$\begin{array}{lllllll}\text { Non-smokers } & 66.61 \pm 7.51 & 64.48 \pm 6.90 & 63.03 \pm 6.91 & 61.09 \pm 6.05 & 0.004^{*}\end{array}$ HR1: The $1^{\text {st }} \mathrm{s}$ heart rate after test $(\mathrm{bpm}), \mathrm{HR} 60$ : The $60^{\text {th }} \mathrm{s}$ heart rate after test (bpm), HR90: The $90^{\text {th }}$ $s$ heart rate after test $(\mathrm{bpm}), \mathrm{HR} 180$ : The $180^{\text {th }} \mathrm{s}$ heart rate after test $(\mathrm{bpm})$, HRR1: Heart rate recovery 1 (bpm) *. Significant.

Mann-Whitney test shows that there are significant differences between PFLs between smoker students and non-smoker students at Universitas Muhammadiyah Yogyakarta. The significance was with $p=0.001(p<0.05)$. The PFLs in non-smokers are higher than in smokers [Table 2].

\section{Discussion}

\section{Participant's characteristic}

Adolescence is growth period between child and adult age [5]. They are the investment for the world. Based on Canadian Pediatric Society [23], adolescence begins with the onset of normal puberty until the individual is mature enough or within the age range of 10 until 19 years old. In this study, all of the adolescents were male [Table 1] which suited the definition of adolescence. There were 65 male adolescents who suited the criteria. They were divided into two groups, 27 smokers and 38 non-smokers.

Increasing smokers have become a serious problem especially among adolescence. Furthermore, in the next 2 decade, it is predicted that 7 of 10 people who die of smoking related diseases would be from the low- or middle-income countries [24].

\section{HR in adolescent smokers and non-smokers}

The HR's characteristics of adolescent smokers and non-smokers are summarized on Table 2. The HR of adolescent smokers is higher than the nonsmokers with $p=0.00(p<0.05)$ on HR1, HR60, HR90, and HR180 [Table 2]. HR is the major predictor of the cardiovascular wellness [25]. The resting HR varied between ages. Normally, for adolescents, the HR ranges around 80-100 bpm [25]. Previous research reported that each cigarette elevated the HR into $20 \%$ from rest baseline and sympathetic stimulation up to $40 \mathrm{bpm}$ [26]. This study shows that the HR of smokers is higher than of non-smokers [Table 2]. It is in accordance with Papathanasiaou et al. [27], who stated that smokers have significantly higher HR than non-smokers. Higher HR has high effect on arterial wall and promotes atherosclerosis plaque [28]. Smoking disturbs the ANS significantly because of the effect of cigarette content. After exercise, the activity of sympathetic stimulation tends to be lower and the HR decreases because of vagal reactivation [27]. In this study, the HR after test declines every minute in adolescent smokers and non-smokers with $p=0.000$ $(p<0.05)$ and $p=0.004(p<0.05)$ [Table 3]. It contrasts with a study on cardiopulmonary function and exercise tolerance in teenagers conducted by Louie [28] that the subjects' HRs in smokers and non-smokers groups increased but there was no significant difference. This study presents that the parasympathetic activity is workable with decreasing HR after test. However, the $\mathrm{HR}$ on adolescent smokers is still higher compared to non-smokers. From this reason above, smoking still gives negative influence for the cardiovascular system. The people with high HR have high risk of cardiovascular disorder and mortality because of the effect of cardiovascular failure.

\section{HRR1 in adolescent smokers and non-smokers}

Increasing HR during exercise is common because of the sympathetic action to fulfill the task of cardiovascular system. Sympathetic activity is withdrawn and vagal reactivation intercedes the rate at which HR declines after the end of exercise. However, after exercise the HR tends to be lower because of the activation of parasympathetic tone. HR decline during recovery is being directly linked with the intensity of post-exercise parasympathetic activity and an important marker of cardiac autonomic control. Abnormal HRR1 is an independent predictor of mortality and directly associated with a higher risk of cardiovascular disease [27].

HRR1 in adolescent smokers and non-smokers in this study represents that there are no significant 
differences between group with $p=0.42(p>0.05)$ [Table 2]. In general, the HRR1 in both groups shows decreased $\mathrm{HR}$ in $60 \mathrm{~s}$ after test with mean $\pm \mathrm{SD}$ $1.83 \pm 0.89$ for adolescent smokers and $1.99 \pm 1.72$ for adolescent non-smokers [Table 2]. In contrast to Erat et al. [20], who stated that HRR1 in smokers delayed. However, in this study, the participants still linier with the theory that HRR decreased within the minutes after exercise [21].

\section{PFL among adolescent smokers and non-smokers}

Table 4 shows that the PFL of smokers is lower than the non-smokers'. It happened because of cigarette contents. The cigarette contents such as nicotine and other substances have harmful properties. They would influence the PFL [7]. Smoking would lead the inflammation of blood vessels then induced the cardiovascular problem [29]. Many reports show that smoking caused the premature death [30]. That is certain that smoking induced endothelial injury [29] and damages the artery. Lesion on artery would decrease the pump of heart. Therefore, it would influence the PFL.

Table 4: The physical fitness level differences among adolescent smokers and non-smokers

\begin{tabular}{llllll}
\hline Group & $\mathrm{n}$ & $\%$ & $\mathrm{PFL} \pm \mathrm{SD}$ & Category & p value \\
\hline Smokers & 27 & $41.53 \%$ & $58.7 \pm 0.984$ & poor & $0.001^{*}$ \\
Non-smokers & 38 & $58.46 \%$ & $80 \pm 0.964$ & good & \\
\hline$*$ S Significant & & & & &
\end{tabular}

Due to that reason above, it is correct to state that smokers have lower PFL than non-smokers as shown on Table 2. Lower PFL will influence the heart health in the future. Similar to Moslemi-Haghighi et al. [31] that physical activity skills in young smokers were decreased and less powerful than non-smokers. In addition, in a study on physical fitness parameters, it was concluded that cigarette smoking reduced the aerobic and nonaerobic power [14].

The smokers have high risk of cardiovascular disease in the future. Nonsmokers in this study have good PFL because there are no harmful substances such as nicotine in their blood. Cardiovascular system of non-smokers is better than smokers. Their level of physical fitness is quite good [Table 4]. Therefore, they have low risk of cardiovascular problem. The limitations of this study were still unclear why HRR1 no significant differences. Then still need more research about HRR1.

\section{Conclusion}

Smoking influences the wellness of the cardiovascular system. The cardiovascular system of non-smokers was better than smokers, especially in PFL and $H R$, but there was no significant effect on HRR1.

\section{Acknowledgments}

The researchers thank to School of Nursing Faculty and Department of Physiology Faculty of Medicine and Health Sciences Universitas Muhammadiyah Yogyakarta and all of their efforts for entries time.

\section{References}

1. World Health Organization. WHO Report on the Global Tonacco Epidemic: Warning about the Danger of Tobacco. Geneva: World Health Organization; 2011.

2. Eriksen M, Mackay J, Ross H. The Tobacco Atlas. $4^{\text {th }}$ ed., Vol. 176. New York: American Cancer Society, World Lung Foundation; 2012. p. 12

3. Kosen S, Usman KA. Indonesain House Hold Survey 1995. Jakarta, Indonesia: Ministry of Health; 1991.

4. Kementrian Kesehatan Republik Indonesia. Profil Kesehatan Indonesia Tahun 2017. Jakarta: Kementrian Kesehatan Republik Indonesia; 2018. p. 217. https://doi.org/10.6066/ jtip.2013.24.2.121

5. Atwater LE. Adolescence. $3^{\text {rd }}$ ed. New Jersey: Prentice Hall 1992.

6. Taylor SE. Health psychology. In: Health-Compromising Behaviour. $3^{\text {rd }}$ ed., Ch. 6. Singapore: McGraw-Hill International Studies; 2006.

7. Gonzalez J, Carpi A. Early effects of smoking on the voice: A multidimensional study. Med Sci Monit. 2004;10(12):CR649-56. PMid:15567981

8. Akoeba $\mathrm{NH}$, Risdiana N. Comparison the level of standard deviation of $\mathrm{N}-\mathrm{N}$ interval (SDNN) among adolescent in non smokers and smokers in Yogyakarta. J Kedokt Kesehatan Indones. 2018;9(6):30-4. https://doi.org/10.20885/jkki.vol9.iss1.art6

9. Cole CR, Blackstone EH, Pashkow FJ, Snader CE, Lauer MS. Heart-rate recovery immediately after exercise as a predictor of mortality. N Engl J Med. 1999;341(18):1351-7. https://doi. org/10.1056/nejm199910283411804 PMid:10536127

10. President's Council on Physical Fitness and Sports. Physical Activity and Sport in the Lives of Girls. Executive Summary. Minneapolis, Minnesota: University of Minnesota; 1997.

11. Shomoro D, Mondal S. Comparative relationships of selected physical fitness variables among different college students of Mekelle University Ethiopia Africa. Int J Phys Educ Fitness Sports. 2014;3(1):7-14. https://doi.org/10.26524/1412

12. Khodnapur JP, Dhanakshirur GB, Bagali S, Mullur LM, Aithala M. Status of physical fitness index (PFI \%) and anthropometric parameters in residential school children compared to nonresidential school children. Physiol J. 2012;1(12):1-5. https://doi.org/10.7439/ijbar.v3i5.454

13. Hapsari EW. The differences of physical fitness and nutritional levels between smoker and non-smoker in male students grade IX of SMP N Tlogowangu Pati 2012/2013. J Public Health. 2014;3(2):2252-6528. https://doi.org/10.25077/jka.v7i3.886

14. Moslemi-Haghighi F, Rezaei I, Ghaffarinejad F, Lari R, Pouya F. Comparison of physical fitness among smoker and non-smoker men. Addict Health. 2011;3(1-2):15-9.

PMid:24494112 
15. Slovic P. Smoking: Risk, Perception and Policy. Thousand Oaks: Sage Publication, American Academy of Political and Social Science; 2001.

16. Lauer MS. Exercise Testing Part 2: The Value of Heart Rate Recovery Cardiol Rounds. Massachusetts: Bringham and Women's Hospital. 2002.

17. Qiu S, Cai X, Sun Z, Li L, Zuegel M, Steinacker JM, et al. Heart rate recovery and risk of cardiovascular events and all-cause mortality: A meta-analysis of prospective cohort studies. J Am Heart Assoc. 2017;6(5):e005505. https://doi.org/10.1161/ jaha.117.005505 PMid:28487388

18. Borresen J, Lambert MI. Autonomic control of heart rate during and after exercise: Measurements and implications for monitoring training status. Sports Med. 2008;38(8):633-46. https://doi.org/10.2165/00007256-200838080-00002 PMid: 18620464

19. Cha KS, Seo MK, Ryu HY, Nam JJ, Sung DJ. Smokingsuppressed heart rate recovery in young male college students who regularly exercised. Iran J Public Health. 2015;44(8):1146-7. PMid:26587480

20. Erat M, Doğan M, Sunman H, Dinç Asarcıklı L, Efe TH, Bilgin M, et al. Evaluation of heart rate recovery index in heavy smokers. Anatol J Cardiol. 2016;16(9):667-72. https://doi.org/10.5152/ anatoljcardiol.2015.6500

\section{PMid:27488749}

21. Cole CR, Foody JM, Blackstone EH, Lauer MS. Heart rate recovery after submaximal exercise testing as a predictor of mortality in a cardiovascularly healthy cohort. Ann Intern Med. 2000;132(7):552-5. https://doi. org/10.7326/0003-4819-132-7-200004040-00007 PMid:10744592

22. Fernando RJ, Ravichandran K, Vaz M. Aerobic fitness, heart rate recovery and heart rate recovery time in Indian school children. Indian J Physiol Pharmacol. 2018;59(4):407-13.

\section{PMid:27530008}

23. HT Lee, HL Roh, YS Kim. Cardiorespiratory endurance evaluation using heart rate analysis during ski simulator exercise and the Harvard step test in elementary school students. J Phys Ther Sci 2016;28:641-645.

24. Smith SC, Milani RV, Arnett DK, Crouse JR, McDermott MM, Ridker PM, et al. Atherosclerotic vascular disease conference: Writing group II: Risk factors. Circulation. 2004;109(21):2613-6. https://doi.org/10.1161/01.cir.0000128519.60762.84 PMid: 15173043

25. Mishra T, Rath PK. Pivotal role of heart rate in health and disease. J Indian Assoc Clin Med. 2011;12(4):297-302.

26. O'Connor K. Smoking, heart rate and personality. Pers Individ Dif. 1993;14(1):225-32.

27. Papathanasiou G, Georgakopoulos D, Papageorgiou E, Zerva E, Michalis L, Kalfakakou V, et al. Effects of smoking on heart rate at rest and during exercise, and on heart rate recovery, in young adults. Hellenic J Cardiol. 2013;54(3):168-77. PMid:23685653

28. Louie D. The effects of cigarette smoking on cardiopulmonary function and exercise tolerance in teenagers. Can Respir J. 2001;8(4):289-91.

PMid: 11565515

29. Pittilo RM. Cigarette smoking, endothelial injury and cardiovascular disease. Int J Clin Exp Pathol. 2000;81 (4):219-30. PMid:10971743

30. Fowler G. Smoking as a risk factor for cardiovascular disease. In: Poulter N, Sever P, Thom S, editors. Cardiovascular Disease Risk Factors and Intervention. Oxford: Radcliffe Medical Press; 1993. p. 161-9.

31. Fukuba $\mathrm{Y}$, Takamoto $\mathrm{N}$, Kushima $\mathrm{K}$, Ohtaki $\mathrm{M}$, Kihara $\mathrm{H}$, Tanaka T, et al. Cigarette smoking and physical fitness. Ann Physiol Anthropol. 1993;12(4):195-212. https://doi.org/10.2114/ ahs1983.12.195

PMid:8373478 